\title{
DOSSIÊ
}

Sociologias, Porto Alegre, ano 17, no 38, jan/abr 2015, p. 44-62

\section{Desafios para uma sociologia política brasileira: os elos entre movimentos e instituições}

\section{Resumo}

O texto visa debater sobre o lugar da sociologia política nas divisões institucionais das ciências sociais e questiona se a mesma se configura como uma área temática ou um recorte disciplinar. Discute sobre as dificuldades que a disciplina enfrenta face a especializações paradigmáticas: dos estudos institucionalista-estatais versus os centrados na cultura política, em especial, da sociedade civil. A seguir, trata do papel de alguns constrangimentos operacionais, metodológicos ou paradigmáticos na produção do conhecimento da sociologia política, como o da existência de uma língua franca para o campo científico e o legado da colonialidade no saber, a partir de centros acadêmicos hegemônicos. Por fim, avalia a relevância de uma abordagem temática para a sociologia política que fortalecesse o diálogo entre enfoques institucionalistas e da cultura-política, buscando aprofundar o conhecimento relativo aos dilemas, conflitos e confrontos entre sociedade civil, movimentos sociais e esfera estatal, no Brasil contemporâneo.

Palavras-chave: Estudos institucionalista-estatais. Cultura política. Movimentos emergentes. Giro descolonial.

$\bar{*}$ Universidade Federal de Santa Catarina (Brasil) 
Sociologias, Porto Alegre, ano 17, no 38, jan/abr 2015, p. 44-62

Challenges to a Brazilian political sociology: the links between social movements and institutions

\section{Abstract}

In this work, I discuss the place of political sociology within institutional divisions of the social sciences, inquiring whether it comprises a subject area or a subfield of a discipline and addressing the difficulties that political sociology faces in view of paradigmatic specializations: that of institutionalist state studies versus those focused on the political culture, particularly civil society. Then, I discuss the role of some operational, methodological or paradigmatic constraints for building knowledge in political sociology, such as the prevalence of a lingua franca in Science and the colonial legacy in knowledge production, concentrated in hegemonic academic centers. Finally, it is estimated the relevance for political sociology of a thematic approach able to strengthen the dialogue between institutionalist and political-cultural perspectives, seeking a deeper understanding of the dilemmas, conflicts and contentions between civil society, social movements and the State in contemporary Brazil.

Keywords: Institutionalist state studies. Political culture perspective. Emerging social movements. Decolonial turn.

\section{Controvérsia conceitual sobre a sociologia política no Brasil: área temática ou recorte disciplinar?}

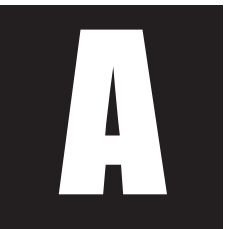

sociologia no Brasil, inicialmente inspirada nos intelectuais do pensamento social brasileiro no século XIX, foi introduzida no ensino apenas em meados da década de 1920 e teve sua institucionalização acadêmica a partir de meados da década de 1930. Nessa década, foram criados os primeiros cursos de Ciências Sociais, quando da fundação da Escola Livre de Sociologia e Política de São Paulo (1933) e da Seção de 
Sociologias, Porto Alegre, ano 17, no 38, jan/abr 2015, p. 44-62

Sociologia e Ciência Política da Faculdade de Filosofia da Universidade de São Paulo (1934), bem como do curso de Ciências Sociais na Universidade do Distrito Federal, no Rio de Janeiro (1934). Entretanto, no âmbito das ciências sociais, a sociologia era a disciplina mais referenciada naquele momento e se desenvolvia frequentemente na interface do debate entre a sociologia e a ciência política, para pensar as representações sociais e políticas, constituindo-se, portanto, numa abordagem que poderia se enquadrar no campo do que posteriormente foi denominado de sociologia política. Essa situação disciplinar se manteve até a década de 1960, quando iniciou a expansão da pós-graduação em ciências sociais. À época, a sociologia ainda mantinha uma relativa hegemonia, o que veio a implicar posteriormente a busca de autonomia institucional da antropologia e da ciência política, as quais, de forma gradativa, foram propondo a abertura de novos programas de graduação e/ou de pós-graduação específicos de suas áreas. Essa transição não se deu sem algumas perdas, conforme observou Liedke Filho:

associados aos esforços de cada disciplina para se apresentar como a ciência social - única e verdadeira - ocorrem, por vezes, divisões institucionais com a criação de departamentos, cursos de graduação ou pós-graduação específicos. Este é um dos casos mais tensos e dramáticos de enfrentamentos interdisciplinares, com o uso de múltiplos expedientes para alcançar a legitimação e consolidação institucional a "todo e qualquer custo" (2005, p. 224).

Nessas circunstâncias, a sociologia política, enquanto abordagem teórico-analítica, e que se encontrava bastante contemplada no interior das ciências sociais, teve de fazer novas opções, seja como área temática no interior das pós-graduações em sociologia e/ou ciência política, ou como pós-graduação especializada, como foi o caso do Programa de Pós-graduação em Sociologia Política da UFSC. As dificuldades encontradas posterirormente para legitimar-se institucionalmente como um recorte disciplinar 
Sociologias, Porto Alegre, ano 17, no 38, jan/abr 2015, p. 44-62

estão relacionadas ao processo de institucionalização das disciplinas mestras das ciências sociais (sociologia, ciência política e antropologia), que trabalhavam para sua autonomia institucional e programática, nas agências de fomento, na academia e nas opções profissionais, e nos concursos públicos. Dessa forma, à sociologia política restava se definir como uma área temática de investigação e/ou como um recorte analítico que contemplasse prioritariamente referenciais das tradições sociológicas e políticas.

Perissinotto (2004) defende a preservação do recorte teórico-interpretativo da sociologia política, apoiando-se em Sartori (1969), para o qual a sociologia política é um "híbrido inter-disciplinar" que conjuga os ensinamentos da sociologia e da ciência política:

Isto quer dizer que o pesquisador influenciado por essa disciplina deve se orientar contra os reducionismos e deve conjugar em suas análises as variáveis típicas da Sociologia (as estruturas sociais) com as variáveis típicas da Ciência Política (as estruturas políticas) (Sartori, 1969, p. 109). A Sociologia Política é, portanto, uma aceitação do fato óbvio, mas atualmente relegado ao esquecimento, de que os sistemas social, econômico e político são interdependentes (Perissinotto, op. cit, p. 205).

Portanto, a sociologia política, no final do século passado, passou a enfrentar dois desafios: por um lado, dialogar ou se integrar institucionalmente às opções por disciplinaridades mais restritas (sociologia, ciência política e antropologia), ressituando-se identitariamente; por outro lado, considerar as novas opções de inter ou transdisciplinaridade ampliadas, abrindo-se para novas parcerias na área das ciências humanas, como com a história, geografia, filosofia, educação, etc., enfrentando um novo desafio pluri-identitário. Do ponto de vista do enquadramento institucional, Irlys Barreira (2013, p. 290), acrescenta que talvez um dos grandes dilemas postos hoje para ciências sociais - acrescentaria aqui a sociologia política - seja a possibilidade de associar a cumulatividade do conhecimento 
Sociologias, Porto Alegre, ano 17, no 38, jan/abr 2015, p. 44-62

com as ofertas institucionais que simultaneamente definem oportunidades de acesso [...] e pontuam a agenda do pesquisador. Nessa direção, os novos recortes disciplinares vieram incidir numa especialização temática que tem levado à divisão da realidade sócio-política em dois campos de investigação e interpretação, os quais orientam a leitura da interação entre Estado e sociedade civil, quais sejam:

1. Da política institucional: tratando a relação do Estado com a sociedade através de abordagens institucionalistas, neo-institucionalistas e da escolha racional, como vem sendo feita especialmente pela ciência política das últimas décadas.

2. Da cultura-política: tratando a relação, a participação e os conflitos da sociedade civil, do terceiro setor, dos movimentos sociais e das manifestações públicas com a esfera governamental e com as instituições estatais, a partir de uma leitura sócio-cultural do sujeito político relativamente autônomo do campo estatal-institucional.

Outro autor que contribui para se pensar a distinção entre essas abordagens é Paulo Krischke (2007), em uma resenha ao livro Introdução à Sociologia Política, de Carlos Sell. Para Krischke, as perspectivas institucionalistas: (1) adotam uma definição minimalista do espaço público, centrando-se nas instituições da governabilidade, (2) focalizam a ação das elites, os partidos e o governo como seus atores relevantes, (3) nas análises do regime, utilizam perspectiva temporal do ciclo de desinstitucionalização e de re-institucionalização do regime e do conjunto de regras e comportamentos governamentais.

Enquanto, para o autor, as abordagens político-culturais: (1) ocupam-se com a expansão da democracia para além das fronteiras do Estado; (2) concentram seu interesse nos 'cidadãos coletivos' como unidade de análise, elegendo os setores sociais subordinados, (3) privilegiam o confronto entre as ações culturais dos movimentos e as instituições do- 
Sociologias, Porto Alegre, ano 17, no 38, jan/abr 2015, p. 44-62

minantes, das perspectivas dos setores subordinados. A questão que se coloca é se seria possível, através de um diálogo 'interdisciplinar' e 'multi-temático' entre as abordagens institucionalistas e da cultura-política, contribuir para uma sociologia política contemporânea na qual as dimensões sociais e políticas fossem contempladas de forma a aprofundar a análise dos encontros ou desencontros, dos conflitos ou da cooperação entre o ativismo civil e o Estado, a partir da democratização do sistema político pós-ditadura militar no Brasil. Remetemos aqui, novamente, à defesa de Perissinotto (2004, p. 228) de uma sociologia política renovada em que a análise das decisões políticas deve[ria] ter como objeto de estudo não apenas as instituições políticas e seus atores racionais, mas deve[ria] incluir também a 'sociedade'. Em outras palavras, deveria superar limitações observáveis, tais como, não se restringir a:

\begin{abstract}
uma análise das instituições políticas baseada no institucionalismo de escolha racional... [a qual] parece ter dificuldades em incorporar os constrangimentos socioeconômicos e culturais, [e], por outro lado, uma Sociologia Política não está [ou não deveria estar] condenada a menosprezar as instituições como variável importante para se entender o processo político (Perissinotto, 2004, p. 227).
\end{abstract}

Essa lacuna em se pensar os dois lados da relação Estado-sociedade vem se colocando como um desafio relevante a partir das novas formas de agir político dos movimentos sociais e/ou das manifestações de rua recentes, sobre o que buscaremos refletir, ainda que de forma ensaística, mais adiante. 


\title{
2. Os impasses da sociologia política em face de constrangimentos acadêmicos institucionais e de construção dos saberes
}

Para se fazer a transição de enfoques científicos condicionados por legados já bem legitimados na academia, é necessário iniciar por uma visão crítica sobre limitações ou constrangimentos operacionais, metodológicos ou paradigmáticos na produção do conhecimento, dentre os quais destacaremos: a existência de tradições que constroem espaços acadêmicos hegemônicos. No contexto dessas tradições, devemos iniciar por uma avaliação da hegemonia da língua inglesa nas ciências, e da produção científica a ela associada, a qual tende a organizar as agendas intelectuais e a pautar os debates acadêmicos e/ou científicos. Maia (2011a, p. 88), referindo-se a Renato Ortiz, afirma que:

\begin{abstract}
a ideia de uma língua franca da ciência ignora a contextualização de conceitos e enunciações, bem como a própria dificuldade de traduzir argumentos em formulações abstratas e desencarnadas. O inglês como língua mundializada produz não apenas hierarquias e barreiras efetivas para publicação e circulação de ideias, como também tem o poder de pautar debates e organizar a agenda intelectual em função de certos problemas (como não pensar nas discussões sobre governance?)... e traduz uma divisão entre local e universal que reflete hierarquias produzidas por hegemonia linguística.
\end{abstract}

Não se pretende aqui sugerir desconsiderar a produção sociológica em língua inglesa, com toda sua diversidade e riqueza interpretativa, mas sim estar abertos para os paradigmas críticos à incorporação muito automática desses conhecimentos, bem como à negligência em relação às várias contribuições latino-americanas no sentido de pensar as realidades locais a partir de sua história, seus desafios e alternativas políticas, de forma mais autônoma em relação à "europeização" dos conhecimentos 
científicos. Nessa direção, numa publicação recente, Lynch (2013) desenvolve argumentos que questionam o posicionamento de autores das ciências humanas brasileira, em suas autocomparações à produção do denominado 'centro' ou do chamado primeiro mundo.

Lynch busca uma explicação para a subalternidade assumida pela sociologia brasileira nascente na sua relação com a tradição europeia da área, especialmente no que diz respeito ao que denominou de autores do 'pensamento político-social brasileiro'. Em síntese, segundo o autor, os intelectuais pós-república e de maneira mais atenuada no avançar do século $X X$, tinham um sentimento de inferioridade acadêmica em relação ao legado das ciências centrais ou europeias. Isto é, a tradição do "pensamento político-social brasileiro" era considerada, por seus formuladores, como um subproduto da teoria (produzida nos países centrais). O autor conclui que:

O pensamento periférico, entendido como um ramo de segunda ordem, qualitativamente inferior ao europeu, porque examinado por meio de critérios como "originalidade", só teria serventia para os membros da própria comunidade igualmente periférica que o produzira. O centro produziria teoria, filosofia e ciência na forma de trabalhos originais e universais; da periferia, só se poderiam esperar pensamento ou história das ideias, plasmados em ensaios sem originalidade ou simplesmente de baixa densidade intelectual. (Lynch, 2013, p. 759).

A questão que se coloca é: em que medida, ao invés da reprodução quase obrigatória das teorias dos 'centros', como ainda se observa em parte dos estudos sociológicos, existe a possibilidade de um desafio sociológico orientado para uma releitura da realidade nacional, para um 'giro descolonial' de coexistência (ética, política, epistêmica) (Mignolo, 2005 , p. 241). Giro que pode ser uma alternativa válida para interpretações atualizadas de nossa sociedade, que não se restrinja à hegemônica leitura ocidental tradicional na academia. Em outras palavras, o melhor caminho a ser recomendado, em especial aos jovens pesquisadores, seria 
o de abertura a desafios diversos de interpretação sociológica, não "obrigatoriamente" apenas centrado na literatura hegemônica na academia.

Nessa direção, encontram-se vários estudiosos do pós ou neocolonialismo latino-americano e do projeto de um "giro descolonial", o qual avança para além da herança colonial do conhecimento na direção de uma nova forma de saber (episteme) e de um novo fazer político emancipatório. Um dos precursores desse pensamento no Brasil foi Guerreiro Ramos que, já na década de 1960, com seu relevante livro sobre a Redução Sociológica, dentre outros, buscou desconstruir o pensamento social e a historiografia brasileira voltados à ideia da democracia racial. $\mathrm{O}$ autor afirmava que no Brasil "não haveria raça", mas haveria "relações raciais" e "racismo". Face ao papel do Estado e das instituições, examinava as transformações sociais, os conflitos e as contradições entre elites e o povo, buscando não reduzir suas interpretações aos legados distantes de nossa realidade histórica ou incorporados acriticamente pela intelectualidade brasileira. Como lembra Nogueira (2007, p. 74), o mito da democracia racial se tornou um obstáculo para o enfrentamento das relações étnico-raciais e sociais, à medida que negros, povos indígenas e mulheres, sobretudo, ficaram submetidos e restritos ao conceito de classe social. Restrição essa que será enfrentada, posteriormente, pelos próprios sujeitos dos movimentos sociais sub-representados nas teorias de classe, como pelas novas abordagens mais inclusivas das situações de subalternidade nas periferias do capitalismo.

Maia (2010), referindo-se aos estudos pós-coloniais, acrescenta que é necessário fazer a releitura do pensamento social brasileiro como uma forma de imaginação fronteiriça que necessita ser estudada, relida, criticada e reaberta em perspectiva comparada. Seguindo Mignolo, acrescenta que

os intelectuais sertanejos (Lima, 1999) seriam os intérpretes desse lugar de discurso fronteiriço, que pensa a modernidade ao mesmo tempo "de dentro" - como homens de elite formados no tempo europeu - e "de fora" - como críticos 
Sociologias, Porto Alegre, ano 17, no 38, jan/abr 2015, p. 44-62

do mal-estar da civilização em espaços regidos por lógicas não coincidentes com a europeia (MAIA, 2010, p. 74).

Por sua vez, a sociologia política não deveria negligenciar a recuperação crítica dessa historicidade não isenta de antagonismos, contradições e diferenças entre nossos legados político-culturais 'desde fora', fruto das tradições europeias, versus os 'desde dentro', fruto das tradições nativas. A sociologia política aplicada aos estudos da sociedade civil e dos movimentos sociais poderá se beneficiar dessa recuperação.

José de Souza Martins, em obra que recupera reflexivamente sua trajetória intelectual à luz da evolução da própria sociologia brasileira, participa desse esforço, ao afirmar que é imprescindível não perder uma dimensão analítica mais interdisciplinar, e sugerir:

[...] a necessidade absoluta do diálogo entre as Ciências Sociais. Em um país que é periferia do mundo civilizado, como é o caso do Brasil, não se pode fazer uma boa pesquisa sociológica na roça se não houver diálogo com a Antropologia e não se usar técnicas antropológicas. Idem, com os historiadores. Por exemplo, Os Parceiros do Rio Bonito de Antônio Cândido tem um grande diálogo com a História e com a Antropologia, sem deixar de ser Sociologia... Nós perdemos isto. Acho que houve uma especialização excessiva, não como decorrência de uma evolução, mas da influência desses estrangeirismos, que acaba pesando muito aqui (MARTINS, 2013, p. 47-8).

Retornando à constituição da sociologia política no Brasil como disciplina, observe-se que Elisa Reis (2002), em entrevista concedida a Revista Política \& Sociedade, destacou como suas temáticas estruturantes no século $\mathrm{XX}$, em primeiro lugar o Estado nacional, porque, em suas palavras, conjuga uma dimensão da solidariedade, que é a nação, e uma dimensão de autoridade, que é o Estado (id, p. 17). A primeira seria mais sociológica, enquanto a segunda, mais política, o que poderíamos pensar como a demarcação do 
Sociologias, Porto Alegre, ano 17, no 38, jan/abr 2015, p. 44-62

início da tensão entre o campo da cultura-política do cotidiano, da sociedade civil, e o campo da política institucional estatal e/ou governamental. Reis aponta. ainda, como temas relevantes para a sociologia política, a cidadania, a relação entre Estado e sociedade civil e a crise de representação entre essas esferas, da qual emergem novas demandas por inclusão, por participação, por representação (id., p. 21). Pode-se observar que esses tipos de demandas se intensificaram a partir do início do século XXI, estando no cerne dos conflitos entre sociedade civil e Estado, conforme expressos nas manifestações de rua, de nossa história recente.

\section{Para uma sociologia política na interface ativismo civil versus esfera institucional}

Uma sociologia política contemporânea que busque compreender os desafios e os conflitos dos movimentos sociais e do ativismo civil, face aos constrangimentos históricos da esfera institucional estatal, deveria realizar a releitura dessa história por meio de uma abordagem descolonizadora do saber, ou seja, é importante inserir a história do pensamento brasileiro em uma história transnacional mais ampla do pensamento periférico (Maia, 2011b, p.71). Iniciaremos indicando algumas das lacunas das temáticas tradicionais na literatura e os desafios para uma sociologia política dos movimentos sociais e do ativismo civil. Os analistas clássicos do pensamento sociopolítico brasileiro, usados por alguns como referência na história da sociologia política brasileira, se dedicaram fundamentalmente à análise do lado hegemônico do poder, no Estado e na cultura-politica, com pouca atenção ao contraditório dos desempoderados na política e na cultura. Por isso, vale a pena deixar registrados alguns temas relevantes a serem revistos a partir de um olhar descolonial contemporâneo, como aqueles que enumeramos a seguir. 
Sociologias, Porto Alegre, ano 17, no 38, jan/abr 2015, p. 44-62

1. Sobre o patriarcalismo, o patrimonialismo, o republicanismo e o movimento abolicionista: será necessário reescrever seu legado a partir da visão crítica dos novos movimentos, tal como está sendo feito, em alguma medida, pelo feminismo, movimentos étnicos raciais, movimentos juvenis, dentre outros.

2. Sobre a ideologia de miscigenação, o movimento eugenista e a posterior ideologia da "democracia racial": será necessário incluir as novas leituras de intelectuais críticos àquele legado e realizar uma apreciação das interpretações do próprio movimento negro sobre o assunto.

3. Sobre o totalitarismo de Estado e a ditadura militar: é necessário confrontar o conhecimento acadêmico consolidado com a produção mais recente sobre e a partir dos atores envolvidos nas lutas contra a ditadura, dos movimentos estudantis e dos movimentos pela democratização, e da respectiva memória histórica que está sendo recuperada, dentre outros.

4. Sobre a globalização da economia, a mundialização do saber e o império na política: será necessário confrontar o saber mais clássico com as contribuições pós-coloniais e interculturais da academia e do ativismo cidadão e da respectiva incidência de suas lutas nas redes sociais e virtuais contemporâneas.

5. Em face da política institucional estatal: será necessário examinar analiticamente as formas e as dimensões de empoderamento e autonomia do ativismo civil e dos movimentos sociais contemporâneos nos processos participativos estatais, e as formas de cooperação e/ou de resistência política entre essas duas esferas, contribuindo, assim, para intensificar na academia o diálogo entre as análises da cultura-política versus as institucionalistas, tema esse que será tratado a seguir.

O último ponto mencionado, por se tratar do mais contemporâneo e por gerar maiores desafios no debate acadêmico, merece considera- 
Sociologias, Porto Alegre, ano 17, no 38, jan/abr 2015, p. 44-62

ções adicionais. Para a análise dos conflitos e das negociações entre movimentos sociais e atores das manifestações públicas com a esfera pública institucional e, em especial, a governamental e a político-partidária, buscaremos examinar a performance de sujeitos sócio-políticos que consideramos paradigmáticos. O objetivo é mapear as possibilidades de uma sociologia política renovada para o século XXI, que trate do tema dos conflitos e colaborações entre sociedade civil e esfera estatal, abordando o ativismo da sociedade civil, representado por movimentos sociais já tradicionais, movimentos emergentes e cidadania de sujeitos em redes; bem como os caminhos trilhados pelos intelectuais para a análise das relações entre ativismo civil e participação institucional.

Os movimentos sociais tradicionais são paradigmáticos para se analisar a transição histórica de sua condição de sujeitos mais autônomos na esfera pública versus sua condição de sujeitos com participação institucional junto à esfera estatal. Busquei analisar essa trajetória com mais detalhes (Scherer-Warren, 2014b), a partir de três momentos constitutivos dos movimentos sociais, seguindo Alberoni (1991), que assim define as possíveis transformações de um movimento: a) o estado-nascente como uma experiência cognoscitiva pessoal ou coletiva - descobrir aquilo que estava oculto - e emocional, entusiasmante e perturbadora (id, p. 13) - a qual estimula os indivíduos e grupos a se engajarem em lutas por mudança social; b) o movimento social propriamente dito, como um processo histórico que vai do estado nascente, com uma proposta inovadora, à institucionalização de suas pautas; c) e que acaba quando a instituição já está consolidada e, mais uma vez, só representa o cotidiano, ou seja, o institucional (id p. 15). Portanto, os movimentos sociais podem vir a percorrer a trajetória histórica que vai do estado nascente à sua consolidação em um movimento social organizado e deste a uma institucionalização completa a partir de sua incorporação definitiva enquanto membro/co- 
letivo engajado nos processos de participação institucional, nesse caso, deixando de ser movimento, segundo Alberoni. Porém, não haverá um determinismo histórico nessa trajetória, sendo possível que o movimento, ao se renovar politicamente no processo de participação institucional e se auto-atribuir novos desafios e demandas de transformação social, direitos humanos e/ou políticas públicas, estará se recriando enquanto movimento social. Por outro lado, as manifestações de rua poderão contribuir para o surgimento de estados nascentes, na medida em que aquecem o ímpeto de um coletivo com vistas a um projeto de mudança social, no sentido de renovar e atualizar suas próprias lutas.

Qual a implicação dessas trajetórias para a disciplina da sociologia política? Trazem a necessidade de substituir as abordagens excessivamente especializadas, conforme já apontamos (centradas na cultura política e autonomia dos movimentos na elaboração de seus projetos de mudança versus aquelas dedicadas à análise da participação na institucionalidade estatal e/ou nos governos), para análises que contemplam a relação entre políticas contestatórias e políticas participativas na esfera institucional. Wampler (2013), em estudo que recomenda a complementação entre essas abordagens para explicar as duas faces dos processos de contestação/ participação institucional, conclui que:

\begin{abstract}
a participação institucional age como uma "escola de democracia", permite novas formas de deliberação no interior das instituições democráticas, e promove o desenvolvimento de redes sociais. É a combinação desses três fatores que gera um poder latente que pode mobilizar e promover politicas de contestação (Wampler, 2013, p.17).
\end{abstract}

Acrescentaria que as dinâmicas dos protestos organizados, das manifestações de rua, e lutas similares contribuem também para a renovação das pautas dos movimentos e para a criação de novas formas de incidência na participação institucional. 
Quanto aos movimentos emergentes, mais recentes no Brasil, observe-se que dentre os que tiveram maior projeção pública estão os Movimentos do Passe Livre e a Marcha das Vadias. Tratam-se de dois movimentos com participação principalmente de jovens e que se orientam, sobretudo, para projetos de mudanças estruturais e culturais na sociedade. Nesse sentido, sua constituição enquanto movimento ainda, em grande medida, em estado-nascente merece ser investigada. Entretanto, com sua visibilidade pública crescente a partir das manifestações de junho de 2013, esses movimentos, juntamente com outros, foram chamados pela esfera governamental para negociações institucionais. Além disso, eles alargaram seus elos de relacionamentos na praça pública e nas acolhidas (ainda que poucas) da esfera institucional. A questão que se coloca é de como estes sujeitos, com uma concepção autonomista em relação à participação política, terão suas performances alteradas, ou não, face às oportunidades políticas institucionais de participação, geradas pelo seu protagonismo nas manifestações de rua de 2013.

Um terceiro segmento na interface entre sujeitos e instituições políticas, que aqui denominamos de cidadania de sujeitos em redes, é uma realidade crescente na sociedade da informação, com destaque para a participação, predominantemente opinativa, estimulada por meio das redes virtuais (Twitter, Facebook e outras), e suas decorrentes participações nas manifestações de rua, respondendo frequentemente a chamamentos políticos individualizados por meio dessas redes virtuais. Esse tipo de participação tem ampliado a visibilidade pública dos eventos políticos, com grande repercussão através das mídias, mas sem garantia de continuidade de engajamento mobilizatório, devido à efemeridade do comprometimento político. Novos procedimentos interpretativos sobre os processos mobilizatórios contemporâneos terão que ser desenvolvidos, conforme já percebido por Moura e Silva. 
Sociologias, Porto Alegre, ano 17, no 38, jan/abr 2015, p. 44-62

Assim, observa-se que o campo de estudos sobre sociedade civil e, mais especificamente, sobre as relações entre os atores sociais e o campo político-institucional ainda apresenta uma ampla agenda de investigação empírica e elaboração teórico-metodológica a ser desenvolvida. É como contribuição para esse desenvolvimento... que a abordagem das redes, seja por meio do conceito de redes de políticas, seja por meio da metodologia de análise de redes sociais, parece apresentar-se como instrumento útil e fértil para os pesquisadores brasileiros (Moura e Silva, 2008, p. 50).

Acrescentaria, a esse desenvolvimento, a necessidade de estudos da participação nas e a partir das redes virtuais e dos modos de participação individualizada, os quais carecem de referência a coletivos políticos mais amplos e politicamente definidos quanto a suas demandas para sua presença nas manifestações públicas. Temos, nessa direção, resultados de surveys sobre as demandas das manifestações de rua de 2013 (Scherer-Warren, 2014a). Porém, trata-se ainda de um espaço pouco explorado por interpretações da sociologia política propriamente dita, nos termos definidos por Reis (op. cit), sobre a construção da solidariedade - no caso, em relação aos pares de manifestantes nas redes; ou da explicitação política dos conflitos e das demandas em relação às autoridades estatais ou opositores políticos na própria sociedade civil.

O intelectual que trabalha na pesquisa sobre movimentos, manifestações, utopias de mudanças e na incidência de suas demandas na esfera estatal e política enfrenta, talvez mais do que em outras temáticas, o desafio da relativa neutralidade na ciência. Ainda que siga os protocolos para uma pesquisa científica neutra, na qual os resultados deveriam retratar de forma objetiva a realidade pesquisada, a própria escolha do universo pesquisado, o que pesquisar e como, ou que perspectiva teórico-conceitual orientará sua análise, implica em decisões orientadas por seus valores civilizatórios. Portanto, será melhor explicitar seus posicionamentos em 
relação a mudanças sociais que considera necessárias e assumi-los como uma opção política consciente. Nessa direção, Medeiros (2013, p. 7), referindo-se ao intelectual engajado, recomenda que:

\begin{abstract}
Ante este panorama de injustiça social, o intelectual deve assim ser capaz de agir, pois compreender não é suficiente. Para além de ter de adequar o seu discurso à heterogeneidade de repertórios socioculturais que transpiram na democracia das ruas e de costurar alianças sociais que transcendem as barreiras nacionais, deve também ter a capacidade de projetar as vozes do movimento na agenda pública e mediática e na arena política.
\end{abstract}

Nas sociedades contemporâneas o intelectual engajado tem se tornado uma realidade bastante frequente, especialmente quando aborda questões como direitos humanos, políticas de inclusão social, racial ou de gênero, políticas de empoderamento de populações subalternizadas, avanços nas políticas públicas, todas questões com alto nível de politização e que merecem ser objeto primordial para um sociologia política contemporânea renovada.

Um exemplo paradigmático da explicitação de posicionamentos políticos de intelectuais brasileiros em relação a uma política institucional foi a elaboração e divulgação de manifestos sobre a implementação de cotas para estudantes negros nas universidades públicas brasileiras. Os intelectuais se dividiram em dois grupos, um contrário e outro favorável às cotas raciais para negros. Este talvez tenha sido um dos momentos em que os posicionamentos políticos ficaram mais explícitos, tendo em vista os argumentos, as contribuições e interpretações diferenciadas, e mesmo opostas, dos cientistas sociais brasileiros. Foram apresentadas releituras conflitantes do pensamento social brasileiro e de outras contribuições das ciências sociais, para examinar uma problemática específica, com alto impacto político para o destino das relações étnico-raciais da nação brasileira e para a formulação de novas políticas públicas institucionais. Análise esta que merece ter 
continuidade a partir dos desdobramentos decorrentes, tanto das ações dos movimentos negros e indígenas, como de novas propostas institucionais de inclusão social desses segmentos. Eis aí uma problemática desafiadora para a sociologia política brasileira contemporânea.

Ilse Scherer-Warren - Doutora em Sociologia pela Université de Paris X, Nanterre (1973), e pós-doutora pela Universidade de Londres (1986-87). Foi pesquisadora visitante na Universidade de Brasília (2004-05). Foi professora adjunta na Universidade Federal do Rio de Janeiro (1974-81) e atualmente é professora titular da Universidade Federal de Santa Catarina, onde coordena o Núcleo de Pesquisa em Movimentos Sociais. É pesquisadora IA pelo CNPq e participa do INCT/CNPq de Inclusão no Ensino e na Pesquisa.>ilse@cfh.ufsc.br

\section{Referências}

1. BARREIRA, Irlys. O trabalho intelectual sob a óptica do artesanato e a cidade como campo de pesquisa. Revista Brasileira de Sociologia. SBS, Vol 1, n.1, Jan/ jul. 2013, p. 275-296.

2. KRISCHKE, Paulo. Resenha: Sociologia Política e interdisciplinariedade. Civitas - Revista de Ciências Sociais, Porto Alegre, v. 7, n. 2, jul.-dez. 2007, p. 152-159.

3. LIEDKE FILHO, Enno D.. A Sociologia no Brasil: história, teorias e desafios. Sociologias [online], n.14, 2005, p. 376-437.

4. LIMA, Nísia Trindade. Um sertão chamado Brasil: intelectuais e representação geográfica da identidade nacional. Rio de Janeiro: ed. Revan, 1999.

5. LYNCH. Christian E. C. Por que pensamento e não teoria? A imaginação político-social fantasma da da condição periférica (1880-1970). Dados - Revista de Ciências Sociais, V. 56, n. 4, 2013, p. 727-762.

6. MAIA, João Marcelo E. Ao Sul da teoria: A atualidade teórica do pensamento social brasileiro. Revista Sociedade e Estado. Vol. 26 N. 2 Maio/Agosto 2011a, p. 71-94.

7. MAIA, João Marcelo E. Space, social theory and peripheral imagination: Brazilian intellectual history and de-colonial debates. International Sociology. Vol. 26, n.3, 2011b. p. 392-407.

8. MAIA, João Marcelo E. O pensamento social brasileiro e a imaginação pós-colonial. Revista Estudos Políticos. Número O - 2010/01. 
9. MARTINS, José de Souza. A sociologia como aventura: memórias. São Paulo, Contexto, 2013.

10. MEDEIROS, Pilar Damião de. O intelectual engagé dos movimentos sociais. Sociologia, Problemas e Práticas [online]. n.73, 2013, p. 79-92.

11. MIGNOLO, Walter D. A colonialidade de cabo a rabo: o hemisfério ocidental no horizonte conceitual da modernidade. In: A colonialidade do saber: eurocentrismo e ciências sociais. Perspectivas latino-americanas. Buenos Aires: CLACSO, Consejo Latinoamericano de Ciencias Sociales, 2005.

12. MOURA, Joana Tereza Vaz de; SILVA, Marcelo Kunrath. Atores sociais em espaços de ampliação da democracia: as redes sociais em perspectiva. Revista de Sociologia e Política, 16 (Supl.), 2008, p. 43-54.

13. NOGUEIRA, João Carlos. A sociologia e a política em Guerreiro Ramos. Brasília, SEPPIR, 2007. Disponível em: http://scholar.google.com.br/ scholar?cluster= 8495589335127616840 \&hl=ptBR\&as_sdt=0,5. Acesso em: jul. 2013.

14. PERISSINOTTO, Renato Monseff. Política e sociedade: por uma volta à Sociologia Política. Política \& Sociedade. PPGSP, v. 3, n. 5, out. 2004, p. 203-232.

15. RAMOS, Guerreiro. A redução sociológica. Rio de Janeiro: Ed UFRJ, 1996.

16. REIS, Elisa. Situando a sociologia política. Política \& Sociedade: Revista de Sociologia Política 1.1, 2002.

17. SARTORI, Giovanni. Da Sociologia da política à Sociologia Política. In: LIPSET, S. M. (Org.). Política e Ciências Sociais. Rio de Janeiro: Zahar, 1969.

18. SCHERER-WARREN, Ilse. Redes e movimentos sociais projetando o futuro. Revista Brasileira de Sociologia. v. 01, n. 01, Jan/Jul. 2013.

19. SCHERER-WARREN, Ilse. Manifestações de rua no Brasil 2013: encontros e desencontros na política. Caderno CRH. Salvador, 2014a. (no prelo).

20. SCHERER-WARREN, Ilse. Movimentos sociais e manifestações de rua no Brasil contemporâneo. Revista "Brésil(s)", MSH, EHESS, 2014b (no prelo).

21. WAMPLER, Brian. Contentious Politics and Participatory Democracy in Brazil. Paper presented at the annual American Political Science Association Meeting. Chicago, Illinois. August 29-September 15t, 2013.

Recebido em: 22/06/2014

Aceite Final: 08/09/2014 